\title{
La administración de justicia en el espectáculo deportivo. Córdoba, años de entreguerras
}

\author{
Justice administration in the sports spectacle. Córdoba, interwar period
}

\author{
Franco Reyna \\ franco2reyna@hotmail.com \\ Universidad Nacional de Córdoba - Instituto de \\ Estudios Históricos - CONICET, Argentina
}

Recepción: 15 Julio 2020

Aprobación: 10 Noviembre 2020

Publicación: 04 Enero 2021

Cita sugerida: Reyna, F. (2021). La administración de justicia en el espectáculo deportivo. Córdoba, años de entreguerras. Trabajos y Comunicaciones, (53), e134. https://doi.org/10.24215/23468971e134

\begin{abstract}
Resumen: El artículo analiza el proceso de institucionalización y normativización de la administración de justicia en el incipiente espectáculo deportivo cordobés de entreguerras. La investigación examina la configuración de un orden jurídico y la organización de estructuras disciplinarias que resultaron fundamentales para regular los comportamientos en la práctica del fútbol y asegurar la paridad ante la ley entre los participantes. Ello contribuyó a dotar de mayores garantías y seguridades al juego y a igualar las oportunidades desde las que todos partían en la competencia, lo que generó condiciones para su progresiva conversión en un espectáculo de masas.
\end{abstract}

Palabras clave: Deporte, Espectáculo, Administración de justicia, Disciplina, Igualdad de oportunidades.

\begin{abstract}
This paper examines the process of institutionalization and standardization of justice administration in the incipient interwar sports spectacle in Cordoba, Argentina. The research explores the configuration of legal order and the organization of disciplinary structures that turned out to be fundamental to regulate behaviors in football practice and to guarantee equality before the law among the participants. All this contributed to confer greater guarantees and security to the game and to equalize opportunities among players, which produced conditions for its progressive conversion into a mass spectacle.
\end{abstract}

Keywords: Sport, Spectacle, Justice administration, Discipline, Equal opportunities.

\section{INTRODUCCIÓN}

Como plantea Julio Frydenberg (2011, p. 59), el desarrollo del fútbol competitivo, así como de cualquier otra práctica deportiva, tuvo una doble dependencia reglamentaria. Por un lado, de la aceptación universal de las reglas propias del juego homologadas por la Federación Internacional de Fútbol Asociado (FIFA), que eran las mismas para todos los contendientes. Por otro lado, del establecimiento de una serie de condiciones y normativas que organizaban la competencia y posibilitaban la participación en ella, las cuales eran fijadas por las ligas locales creadas a ese fin. Con respecto a esta última, uno de los aspectos primordiales que requería la definición de consensos era la administración de justicia deportiva, en cuanto a los actores, prácticas, criterios 
y estructuras implicados en la sanción y aplicación de normas que regulan la disciplina en las relaciones entre las personas y las instituciones. Sobre dicho asunto trata este artículo.

El caso estudiado se centra en el fútbol de Córdoba y en la entidad federativa que organizaba su ejercicio a nivel local, la Liga Cordobesa de Fútbol (LCF). Tras las dos décadas iniciales en las que el juego se difundió en la ciudad y se reglamentaron competencias periódicas entre equipos de potencial económico y social variado, en los años de entreguerras el deporte vivió una serie de transformaciones que la convirtieron en un espectáculo consumido por una población cada vez más numerosa. El sistema competitivo también experimentó un proceso de adecuación y contribuyó a su dinámica expansiva gracias, entre otros aspectos, a su progresiva mercantilización y a la creciente institucionalización de un entramado disciplinario y coercitivo que normalizara el desenvolvimiento de la actividad y proveyera condiciones ecuánimes de participación.

En ese marco, el artículo analiza el proceso de configuración y formalización de un orden jurídico en el incipiente espectáculo deportivo para prever regularidades y hacer frente a situaciones inconsistentes y conflictivas en su desarrollo. La investigación se concentra en la organización de estructuras regulatorias de la competencia deportiva, la racionalización y codificación de las conductas y la aplicación de castigos a los hechos punibles. A partir de ello, se pretende dilucidar cómo fue cambiando la administración de justicia a medida que el fútbol se iba transformando en un espectáculo de masas, al mismo tiempo que se procura evaluar la manera en que este proceso influyó en el equilibrio deportivo entre los diferentes agentes.

Desde una mirada enfocada en la articulación de espacios relaciones entre actores desigualmente dotados, el trabajo sostiene que la sanción y modernización del orden jurídico de la LCF fue fundamental para regular comportamientos controversiales, arbitrariedades y transgresiones a principios éticos de la competencia deportiva que alteraban su funcionamiento y afectaban la igualdad de oportunidades desde la que debían partir todos los participantes en el juego. Se trataba de acuerdos sociales propios de la lógica liberal de la época que definían los términos de la asociación e intervención de los sujetos y las instituciones en una práctica recreativa colectiva, donde la esfera disciplinaria se regía como una materia de índole privada. Si bien la equidad reglamentaria no estaba destinada a revertir las desigualdades históricamente acumuladas, su creciente sistematización dotó de mayores garantías y credibilidad institucional al desarrollo del espectáculo y generó condiciones para su democratización y masificación.

Para dar cuenta de esta problemática, se recurrió a los propios documentos elaborados por la LCF y a información brindada por los principales periódicos locales. Con base en ellos, el artículo identifica, en primer lugar, las formas en que se organizó el espectáculo deportivo y su régimen disciplinario a fin de regular la multiplicidad de expresiones violentas e ilícitas en el juego. A su vez, indaga en la instrumentación del marco reglamentario en los partidos y los sentidos de justicia imperantes en la práctica. Finalmente, examina la emergencia de nuevos mecanismos y estructuras jurídicas para asegurar el orden y la seguridad de los espectáculos.

\section{LA ORGANIZACIÓN DEL ESPECTÁCULO DEPORTIVO Y DE SUS MARCOS DISCIPLINARIOS}

Desde el momento en que los diferentes grupos de individuos que se proponían practicar fútbol se asociaban y organizaban en clubes para poder competir contra otros semejantes, seguían las leyes del juego establecidas en Londres por la Football Association. A fin de formalizar algún tipo de competencia periódica que enfrentara a todos entre sí y consagrara a un ganador, tal como sucedía en cada lugar donde se promovía el deporte, los equipos intervinientes crearon entidades federativas que uniformaran su desarrollo y definieran aspectos administrativos entre los afiliados: requisitos para inscribirse y participar de los torneos, reglamentos, categorías, cronogramas, aspectos disciplinarios y fiscales y premios, entre muchos otros.

Así, a partir de 1905 se crearon las primitivas ligas locales para el desarrollo del fútbol en Córdoba (la Liga Cordobesa de Foot-ball y la Liga Central). Recién en 1913 se formó la Federación Cordobesa de Football, entidad que, con estatutos y reglamentos claramente delimitados, fue capaz de organizar, controlar 
y fomentar la práctica del fútbol local hasta la actualidad. La institución, poco tiempo después denominada Liga Cordobesa de Football, ejercía la representación oficial del fútbol en la ciudad y se afilió a la Federación Argentina de Football, la cual regía los destinos del fútbol nacional y organizaba las relaciones entre las afiliadas y con el exterior.

La LCF, como cualquier otra federación local, contaba con autonomía para fijar sus criterios de participación y decidir cómo administrar justicia hacia su interior. Desde esa posición estableció los marcos normativos y disciplinarios que guiaran las relaciones entre personas e instituciones y aseguraran la igualdad formal en las condiciones de competencia entre sus miembros. Todos los participantes depositaban su confianza en ella para que regulara los comportamientos de los adversarios dentro de cánones reglamentarios ecuánimes. Como sugiere Diego Roldán (2012, p. 161), las reglas formaron el componente disciplinario del deporte, un entramado que debía respetarse para alcanzar la victoria legitima.

En efecto, a partir de la década del diez se multiplicaron la cantidad de jugadores, equipos y aficionados del fútbol cordobés y crecieron las rivalidades entre los clubes en la búsqueda del éxito. Desde entonces, tanto en los campos de juego como en la gestión administrativa de la competencia proliferaron cada vez más irregularidades y situaciones conflictivas que afectaban el equilibrio competitivo entre los rivales, ponían en riesgo el normal desenvolvimiento de las actividades deportivas e institucionales y comprometían la asistencia de ciertos aficionados a los espectáculos. Esos hechos involucraban a todos los actores del espectáculo deportivo en sus diferentes roles. Algunas de las prácticas más habituales eran, por parte de los jugadores, las amenazas y agresiones físicas y verbales a árbitros, compañeros, rivales y periodistas, la desobediencia a las autoridades, las firmas simultáneas por diferentes equipos o la aceptación de dádivas para jugar; de los dirigentes, las inclusiones indebidas de jugadores, los pagos de sobornos o las compras ilegales de pases; del público, las invasiones a los campos de juego, los robos y destrozos de instalaciones o el consumo de alcohol; de los referees, las ausencias o la parcialidad en sus fallos.

Ante este panorama, fueron constantes los reclamos e intervenciones de diversos sectores del universo deportivo y la prensa para reprimir y detener esos sucesos, "civilizar" la práctica deportiva y asegurar mejores condiciones y seguridades para su desarrollo. La organización del espectáculo precisaba, en efecto, de una modernización del aparato normativo y de los mecanismos de control vigentes y una mayor institucionalidad y autonomía de sus entes reguladores. En otras palabas, se requería la intermediación más eficiente de organismos soberanos con facultad para resolver sobre cuestiones jurídicas y legitimidad para ser respetados.

$\mathrm{Al}$ respecto, desde esos años la LCF reunió y centralizó información sobre los diferentes agentes que participaban de sus competencias y generó dispositivos para poder identificarlos y registrarlos dentro de la federación deportiva según sus roles (como jugadores -divididos en diferentes categorías-, dirigentes o árbitros) y su adscripción asociativa, con lo que se borraban las diferencias sociales existentes entre ellos. Algunos de los mecanismos empleados fueron la impresión de carnets; ${ }^{1}$ la instauración de planillas en los campos de juego que debían firmar los jugadores y los linesman; ${ }^{2}$ y la creación de un registro de firmas de los jugadores al inicio de la temporada, a fin de cotejar con la rúbrica que hacían en las planillas en cada encuentro. ${ }^{3}$ Además, se comenzaron a documentar los pases de jugadores a otros clubes o ligas. ${ }^{4}$ Estas innovaciones daban cuenta de la modernización institucional de la LCF en pleno proceso de lo que Mercedes García Ferrari (2018, pp. 32-34) señala como construcción de un sistema documentario en la Argentina en las primeras décadas del siglo XX: su función era no solo probar la identidad individual, sino certificar la habilitación para el desempeño de una función o una pertenencia asociativa en el marco de la masificación de la práctica del fútbol.

Por otro lado, la LCF estableció nuevos circuitos burocráticos en la gestión de la justicia deportiva a partir de la implementación de procedimientos administrativos rutinarios. Uno de ellos fue la exigencia a árbitros, en tanto máximas autoridades en los campos de juego, de redactar informes sobre lo acontecido en cada partido. El documento resultante tenía validez legal oficial y debía ser entregado a la entidad federativa para iniciar los correspondientes expedientes. Asimismo, la LCF elaboró reglamentos y, posteriormente, códigos 
para la unificación y tipificación de los delitos y sus castigos, dotó de poder a autoridades con capacidad para juzgar los hechos y confeccionó registros como el Libro de Penas, donde identificaba y clasificaba las penas y sus autores. ${ }^{5}$ Además, utilizó diferentes medios para la publicitación de los castigos y la notificación a los sancionados como las Actas del Consejo Directivo -donde participaban delegados de los clubes- y la prensa. Este proceder fue acompañado por acciones de carácter formativo y preventivo en torno a las conductas deportivas, como la organización de conferencias y la difusión de discursos públicos por parte de las autoridades.

En general, todos estos instrumentos fueron medios materiales y simbólicos creados por la LCF para disponer de información personal de sus miembros y para organizar y moldear sus interacciones en las asociaciones deportivas. A través de ellos sistematizaron la administración de justicia en el ámbito de su jurisdicción y redefinieron las relaciones de poder entre sus actores mediante normas jurídicas de orientación liberal tendientes a la igualación de oportunidades ante la ley. En adelante, el trabajo se va a enfocar en las transformaciones y adaptaciones experimentadas en este proceso de cambio tanto por los agentes del orden deportivo como por los organismos disciplinarios y sus instrumentos de codificación y sanción.

\section{El ARBITRAJE EN LOS CAMPOS DE JUEgo}

Los referees encarnaban la autoridad principal en la administración de justicia en los terrenos de juego y tenían la responsabilidad de garantizar la equidad en la aplicación de las normas. Eran figuras teóricamente imparciales y con un saber especializado que hacían cumplir las reglas del juego, amparados en la condición irrevocable e inapelable de sus fallos que estas les conferían. Además, velaban por el cumplimiento in situ de los marcos normativos y disciplinarios establecidos por la liga que organizaba las competencias bajo su jurisdicción, al tiempo que ellos mismos también estaban sujetos a esas regulaciones. De allí que en este punto interesa reconstruir a los actores que realizaban esta tarea, las condiciones en las que la desarrollaban, las formas en que se organizaron y las prácticas y representaciones en torno a la actividad.

La presencia de los árbitros en el juego era ineludible. Desde que se instauraron los primitivos torneos locales, ejercían el cargo los jugadores, ex jugadores o dirigentes que conocieran los reglamentos del deporte y se ofrecieran voluntariamente para cumplir ese rol. Eran secundados en sus funciones por dos jueces de línea, quienes eran seleccionados por cada club de entre sus miembros.

Con la creación de la LCF en 1913 y el progresivo aumento de partidos a disputarse tras la regularización de las competencias, el arbitraje fue adquiriendo mayor formalidad en la escena deportiva. A diferencia de los reglamentos de las entidades federativas predecesoras, los de la nueva liga dispusieron una sección específica sobre el ejercicio de estos a fin de delimitar sus mecanismos de elección, funciones y atribuciones. En ellos se estipulaba que debían aprobar un examen de competencia que los hiciera acreedores de un título oficial. No podían acceder a este quienes hubieran cometido faltas graves en las canchas o carecieran de "autoridad moral”: esta condición estaba asociada al carácter civilizado que se le adjudicaba a la profesión, pero su determinación quedaba supeditada a criterios subjetivos de los dirigentes. Su designación para los partidos era hecha por el club local dentro de los candidatos oficiales de la Liga y debían contar con el consentimiento del rival. El referee representaba a la Liga en los partidos y debía aplicar penas disciplinarias a los infractores, controlar el uso del uniforme reglamentario y remitir a los encargados un informe sobre los hechos anormales sucedidos durante el desarrollo del partido y sobre las irregularidades observadas en las instalaciones y el juego. A su vez, también eran objetos de sanciones cuando se les probaba parcialidad manifiesta en su accionar, desconocimiento de las reglas o incumplimiento de funciones, ${ }^{6}$ lo que afectaba el normal funcionamiento del espectáculo y lesionaba el principio de ecuanimidad entre los competidores.

Un momento de inflexión para el arbitraje fue la creación de entidades asociativas entre sus miembros: la Asociación de Referees de Córdoba (1915) y su sucesora Asociación de Referees de Córdoba (1921). Ambas contaban con el aval de la máxima entidad rectora del fútbol en la ciudad, y reproducían el perfil de sus 
símiles ya existentes en Buenos Aires y Montevideo. Las entidades aportaron un marco referencial más claro y orgánico para la actividad y permitieron aunar los intereses de sus integrantes y bregar por sus derechos. Entre sus objetivos estuvieron la formación y certificación de sus miembros, su defensa corporativa y la difusión de las reglas de juego. A partir de 1915 se encontraron referencias en la prensa de que los árbitros comenzaron a percibir una remuneración por sus servicios, aunque recién para 1923 existen datos más certeros al respecto: en negociaciones con la LCF acordaron honorarios por partido, a ser abonados en partes iguales por los clubes contendientes. Aunque la norma disponía esa equivalencia, no distinguía entre entidades con diferente capital económico. Tampoco los partidos se pagaban todos por igual, sino que se establecían montos en función de la categoría a la que correspondían: en los de primera división, 10 pesos; en los de intermedia y en los de segunda, $\$ 5{ }^{7}$ Este incipiente proceso de mercantilización del arbitraje fue también una forma de incentivar la postulación de candidatos.

La creación, poco tiempo después, de una comisión de referees en el seno mismo de la LCF significó la cooptación de sus iniciativas asociativas y la subordinación de sus demandas e intereses al órgano directivo del deporte local. Sin embargo, promovió también una injerencia más directa de los árbitros en los asuntos que atañeran al ejercicio de su profesión con relación a la organización de la competencia. ${ }^{8}$

A pesar de todas estas innovaciones en el campo arbitral, a lo largo de estas décadas la disponibilidad de candidatos no fue proporcional a la demanda existente. Entre otros aspectos, con la masificación del deporte cambiaron la concepción y las condiciones del arbitraje. Lo que nació como una labor distinguida en el contexto de una práctica caballeresca, paulatinamente se fue transformando en una institución ambigua y controvertible: si bien todavía conservaba cierto prestigio, empezaba a ser objeto de impugnaciones y a estar sujeta a discrepancias y hostilidades por parte de jugadores, dirigentes y espectadores. Ese era uno de los principales motivos por el que no surgían nuevos postulantes y por el que los pocos ya efectivos rehuían a la dirección de encuentros o faltaban a los compromisos con bastante asiduidad y sin justificativos. Además de la ausencia de garantías necesarias para resguardar su seguridad, los pobres incentivos materiales a su tarea o las falencias organizativas (información errónea sobre los eventos) agravaban la situación.

Ya en 1915 existían quejas en los periódicos sobre el asunto. De los 77 partidos que debieron haberse jugado en la sexta fecha del campeonato, se suspendieron 47 , la gran mayoría por falta de árbitros. ${ }^{9}$ Una década después, las dificultades persistían, por lo que, para conseguir aspirantes, la Liga pedía a las instituciones que remitieran listas de candidatos. En 1926 estaban inscriptos 26 referees oficiales, de los cuales 16 pertenecían a clubes locales; a ellos se agregaban 12 referees honorarios. ${ }^{10}$ Cabe aclarar que, en un fin de semana promedio de ese mismo año se disputaban 35 partidos correspondientes a los torneos locales. Como no todos los árbitros estaban disponibles para cada una de las fechas, su número resultaba insuficiente para la cantidad de encuentros.

Ante ese panorama, los impulsos asociativos en el sector no cesaron y en 1930 fue creada la Asociación Cordobesa de Árbitros de Football (ACAF). Fundamentada en la necesidad de optimizar la selección y capacitación de los jueces y propiciar un mayor control de sus desempeños, sancionó una reglamentación en la que se reservaba el derecho a apelar las penalidades que la LCF aplicara a sus socios. ${ }^{11}$

Los estatutos de la liga de 1930 reconocieron a esta asociación como la representante del conjunto de los jueces que participaban en sus torneos. Para evitar conflictos de jurisdicción con la Comisión de Referées existente en la LCF, se dejaron asentadas las funciones de esta última: examinar candidatos, resolver sobre sus ascensos y descensos y sobre las recusaciones que se les realizaban y explicar cuestiones técnicas propias del juego. Al mismo tiempo, los estatutos dispusieron normativas para organizar a los árbitros y regular más eficazmente su accionar. Al respecto, se los clasificó según sus condiciones y se establecieron nuevos requisitos de admisión. Las tres categorías definidas eran oficiales (debían aprobar un examen teórico y práctico), honorarios (rendían solo el práctico) y Ad-Hoc (nombrados con el acuerdo entre los capitanes de equipo en la misma cancha, por ausencia del titular). Para el acceso a los primeros dos rangos era necesario ser mayor 
de edad, saber leer y escribir satisfactoriamente y adolecer de defectos físicos, todo lo cual debía permitir el correcto desempeño de sus funciones tanto en el juego como en los procedimientos burocráticos exigidos. Además, debían ser de "conducta y moral intachable", lo que vedaba a los condenados por la justicia por delitos contra las personas o la propiedad hasta pasado dos años, los "ebrios habituales" o los jugadores y aficionados castigados por faltas graves en las canchas. ${ }^{12}$ En todos los casos, se investía a los árbitros como autoridades competentes intermediarias entre los deportistas y la Liga y como depositarios y jueces de la moral en el terreno de juego. Para su desempeño estaban obligados a usar uniformes reglamentarios y no debían permitir jugar a los futbolistas que no llevaran los propios. Los estatutos también fijaron con más precisión los viáticos que percibían por partido.

Una de las principales tareas que se desarrollaba en sus recintos era el dictado de conferencias sobre reglas del juego para los colegas y demás deportistas. Incluso, se recurría a referees de prestigio nacional que intervenían en el campeonato porteño para que dieran conferencias radiotelefónicas. Así, los medios de comunicación modernos también eran puestos al servicio de la democratización de saberes técnicos en el campo deportivo. A su vez, como parte de ese proceso de mayor estructuración y especialización de su accionar, la LCF comenzó a exigir a los árbitros certificados médicos y la aprobación de exámenes para su ingreso como aspirantes. ${ }^{13}$

Una vez sancionado el profesionalismo del fútbol local en 1933, los referees no quisieron ser discriminados de los supuestos beneficios económicos de ese fenómeno y comenzaron a exigir un aumento en los honorarios. ${ }^{14}$ La LCF sancionó un incremento proporcional al monto recaudado por entradas a los partidos, ${ }^{15}$ pero la oferta inicial fue catalogada de insuficiente por la asociación de árbitros, ya que solo favorecía, y en parte, a los que dirigían en primera división. La entidad instaba por el trato igualitario hacia todos sus miembros, no solo a aquellos que eran parte de los espectáculos de mayor nivel. El conflicto alcanzó su punto más álgido desde el momento en que se declararon en huelga hasta que no se resolviera favorablemente su reclamo, el cual terminó siendo rápidamente atendido. ${ }^{16}$ Conscientes de ser un actor imprescindible para el desarrollo del espectáculo, los árbitros utilizaron esa forma de protesta, exportada desde la experiencia deportiva porteña o desde la esfera laboral, como un eficaz recurso de presión. Sin embargo, las tensiones con los clubes estuvieron siempre presentes, ya que estos se quejaban permanentemente de los costos que les implicaba el arbitraje.

De esta manera, la ACAF fue adquiriendo peso en la representación de los intereses y derechos colectivos de sus asociados y conformándose como un actor con cierta autonomía y poder de negociación frente a la LCF, aunque esta conservara en última instancia la capacidad de decisión y control. Sin embargo, su accionar no se circunscribió a la puja por sus remuneraciones, sino que también terció por mejoras en sus condiciones laborales y para ofrecerles mayor protección. La colocación de alambrados olímpicos en casi todas las canchas fue uno de los grandes progresos para su labor, ya que le brindaba mayores garantías a su ejercicio ante las continuas invasiones del público a los campos de juego; más aún, fue un elemento que mitigó el poder intimidante y coercitivo de las hinchadas que probablemente influían en los fallos arbitrales, atenuando las ventajas que los clubes que contaban con ese hándicap podían obtener sobre sus rivales.

Además, cuando algunos de sus afiliados sufrían percances en el cumplimiento de su labor, la ACAF ofrecía amparo colectivo al damnificado y se presionaba a la Liga o a clubes particulares para resolver la situación. Una medida recurrente era la de disponer que ninguno de sus árbitros dirigiera partidos en los que actuaran quienes los hubieran agredido hasta tanto el cuerpo directriz local no tomara resoluciones al respecto. Por otro lado, cuando los órganos disciplinarios de la LCF sancionaban a referees, los conflictos entre las entidades se tornaban corrientes, asumiendo el centro la defensa colegiada de sus asociados. ${ }^{17}$

En relación con este último punto, a lo largo de estos años también se fueron incrementando los controles disciplinarios sobre los referees. En primer lugar, se establecieron nuevos mecanismos de prevención de irregularidades en su accionar. Entre otras medidas que evitaran suspicacias, la ACAF pedía a sus referees 
asociados que dieran a conocer la entidad a la que pertenecían, a fines de descartarlos para dirigir partidos que las involucraran. Además, se decidió empezar a escoger a los dos jueces de línea de manera neutral: hasta el momento, estos eran nombrados por cada club, por lo que las constantes acusaciones de favoritismos eran factor de incidentes. ${ }^{18}$

A su vez, también se fueron especificando los factores sujetos a sanción y se fijaron las penas a aplicar por los organismos directivos de la LCF. Algunos de los motivos de apercibimiento, suspensión o destitución de árbitros eran: no presentarse a dirigir o no hacerlo satisfactoriamente, manifestar parcialidad, no informar un incidente o exagerarlo, declarar en forma falsa o confiar la redacción de informes a un tercero, no usar uniforme o dejar jugar a los futbolistas sin que usaran el propio y no hacerlos firmar las planillas. Otros aspectos punibles eran la agresión a los jugadores, la tolerancia al juego brusco y a las protestas y retrotraerse de sus propios fallos ante protestas e invasiones del público.

La denuncia y/o condena por estas causas ponía en juego la reputación pública de los inculpados, lo cual también condicionaba la disponibilidad de agentes. En épocas pretéritas, más de una vez los castigos fueron interpretados por los referees como una afrenta a su probidad e, incluso, algunos optaron por retirarse de la actividad. Sady Moreau, por ejemplo, tomó esa determinación tras ser apercibido por el Consejo Directivo de la Liga por omitir datos de un incidente. ${ }^{19}$ Recién desde los años treinta los árbitros fueron accediendo a un mayor respaldo corporativo e institucional para su accionar ante estas situaciones, lo cual se vio materializado en un repunte en la actividad: hacia 1934, la cantidad de asociados a la ACAF era de $35 .{ }^{20}$ Sin embargo, siguieron recurriendo a la prensa cuando su honor era puesto en juicio, tal como lo hizo Enrique Mansilla para explicar las resoluciones tomadas en un partido por el que había sido recriminado. ${ }^{21}$

Un nuevo hito en el proceso de institucionalización del arbitraje fue la creación de una Comisión Técnica de Referées dentro de la LCF en 1936, en reemplazo de la antedicha Comisión de Referées y como respaldo al accionar del contemporáneo Tribunal de Penas (analizado en el siguiente apartado). Además de asumir las funciones ya asignadas a su predecesora, pasó a ser la encargada de la designación de los jueces de los partidos a través de la implementación de sorteos como innovador mecanismo de selección con el fin de lograr mayor transparencia. $^{22}$

Hacia fines de 1939 es posible reconstruir una estadística fiable de la organización de los referees locales y sus formas de retribución gracias a los registros de cómputos y penas aplicadas brindados por el Tribunal Calificador de Referees. Este era un ente dependiente de la LCF de reciente creación que pasó a regular la actividad arbitral. Tal como consta en sus actas, en total había 32 referees que participaron de 756 partidos oficiales de la LCF; el que más había dirigido tenía 56 y el que menos, 6. Sus remuneraciones variaban entre los $\$ 20$ para los partidos dirigidos en primera, $\$ 5$ para los de segunda, $\$ 4$ para los de cuarta especial y $\$ 2$ para los de tercera, cuarta y quinta. El que más cobró reunió la suma anual de $\$ 465$, contra $\$ 8$ del que menos percibió. ${ }^{23}$ Del mismo modo que los jugadores profesionalizados, el arbitraje también se convertía en un medio para obtener ingresos complementarios a su fuente laboral, ya que solo requería algunas horas de los fines de semana.

Una mirada microanalítica a la trayectoria de uno de los principales referentes que tuvo el referato local puede ayudar a resumir, desde una experiencia subjetiva, aspectos esenciales de la evolución de la actividad arbitral a lo largo de estos años. Don Jerónimo Oyola, de él se trata, fue uno de los fundadores y dirigentes del club Peñarol, rol que compartía simultáneamente con su labor como árbitro oficial de la LCF. En sus propias palabras, alcanzó ese título una vez que llegó a comprender el juego y perfeccionó sus conocimientos tras actuar varios años dirigiendo en divisiones inferiores. Su aspiración de convertirse en árbitro de primera se cumplió en 1916, cuando tras el ausentamiento del referee, fue elegido por los capitanes para el puesto. Posteriormente cumplió todos los requerimientos para ser nombrado oficialmente y se afianzó en las máximas categorías. 
Oyola era reconocido por su compromiso en el ejercicio de la actividad. Además de dictar conferencias sobre aspectos reglamentarios del juego, también participó de las diversas experiencias asociativas emprendidas por los árbitros, siendo uno de los socios fundadores de la ACAF. Otra cualidad que se le destacaba era que, a pesar de estar sometido constantemente a distintos tipos de maltratos como la mayoría de sus pares, rara vez se ausentaba a los partidos y, si lo hacía, era de los pocos que se justificaba con la debida antelación. Como anécdota al respecto recordaba que, dirigiendo un clásico entre Talleres y Belgrano, espectadores de ambos equipos invadieron el campo de juego protestando una jugada y en ese tumulto le robaron el reloj. ${ }^{24}$ Como recompensa a la responsabilidad demostrada en sus funciones, en 1927 creía merecer el premio al referee que dirigía el mayor número de partidos de primera en una temporada, galardón instituido por la LCF como incentivo para combatir el ausentismo. Al consagrarse como ganador su colega Rodolfo Sammartino, Oyola pidió la reconsideración del resultado, dado que alegaba que él no pudo ser acreedor del premio por haber sido injustamente sancionado por una falta que no era merecedora de castigo. ${ }^{25}$

No obstante, su elección como miembro de la Comisión de Referees de la Liga fue una de las máximas distinciones en su carrera. Oyola vislumbraba en la entidad un factor de adelanto para el fútbol porque de ella dependía la premiación de las buenas jugadas y la represión de las acciones que "afeaban" al deporte. A su entender, el arbitraje era un servicio fundamental no solo para el desarrollo del juego, sino también para la custodia de los valores civilizados en el ámbito.

Paradoja del destino, Oyola dejó su vida en un campo de juego. En 1939 se produjo el deceso de esta popular figura mientras dirigía un encuentro. Recientemente había festejado sus bodas de plata en el referato y ocupaba el cargo de vicepresidente de la asociación de referees. ${ }^{26}$ Sin dudas, fue uno de los principales exponentes del arbitraje local, por lo que la reconstrucción de su trayectoria permite vislumbrar las vivencias y contingencias atravesadas por uno de los actores centrales del espectáculo en sus quehaceres en la administración de justicia deportiva.

\section{LOS ORGANISMOS DISCIPLINARIOS Y SUS INSTRUMENTOS DE CODIFICACIÓN Y SANCIÓN}

La administración de justicia deportiva era potestad no solo de los referees en los campos de juego, sino también de los dispositivos disciplinarios dispuestos por la LCF fuera de ellos para regular el funcionamiento del conjunto del sistema competitivo y asegurar igualdad de oportunidades entre los participantes. Aunque cada club tenía sus reglamentos internos para definir atribuciones y dirimir conflictos en el marco asociativo, las diferentes ligas y federaciones que regulaban las competencias configuraron y codificaron sus propias estructuras organizativas y punitivas.

Desde la fundación de la LCF, el Consejo Directivo (CD) era el encargado, entre otras atribuciones, de dictaminar e interpretar las reglas de comportamiento deseadas y punibles en la práctica deportiva y hacer cumplir las sanciones aplicadas. El cuerpo estaba formado por el presidente de la Liga, un delegado de cada club de primera división y, hasta 1935, de dos delegados por los clubes restantes. ${ }^{27}$ En reuniones semanales se trataban los informes que los referees escribían sobre cada partido, las denuncias recibidas y se resolvían los asuntos disciplinares. Cuando algunos de los hechos debatidos no quedaban clarificados, intervenían subcomisiones de investigación, protestas y reglamentos y se abrían pesquisas en las que se podía recurrir al testimonio de los implicados.

Con el fin de respaldar su actuación disciplinaria, el CD unificó y sistematizó el conjunto de hechos percibidos como contravencionales para el desarrollo del juego y del espectáculo mismo, así como también su consiguiente prevención y castigo. Al respecto, los Reglamentos Generales -aprobados desde la creación de la LCF- y los Códigos de Penas -instaurados desde la década del veinte- delimitaron las conductas penadas con el objetivo de ponerlas en conocimiento público, evitar arbitrariedades en su regulación y brindar seguridad jurídica en el ámbito deportivo. La prensa, imbuida en una función pedagógica y civilizadora en 
torno al deporte, colaboró con la difusión de las normas desde los periódicos. Así, contribuía a mitigar el desconocimiento general sobre las infracciones y sus consecuencias y a prevenir y sancionar públicamente situaciones violentas o deshonestas.

Los reglamentos originales de la LCF, además de versar sobre las condiciones, derechos y obligaciones de los diversos actores del juego, contemplaban sanciones para determinados comportamientos, sobre todo de los jugadores. Sin embargo, un gran número de transgresiones no estaban individualizadas o no tenían asignados sus correspondientes castigos. Por ejemplo, en el reglamento de 1916 ya se prohibía la percepción de remuneraciones por jugar y aparecía la descalificación como pena a aplicar, aunque no se aclaraba su duración. La prescripción a "jugar en forma violenta" pecaba de genérica y solo era "pasible de pena disciplinaria", como también lo era la de "hacerlo sin su uniforme". En cambio, los incidentes estaban mejor estipulados: las discusiones y agresiones físicas contra referees se penaban respectivamente con un mínimo de tres partidos y la suspensión anual; los actos hostiles entre rivales se sancionaban con cuatro partidos al agresor y dos al que le repelía. Además, el abandono sin consentimiento del campo de juego durante el partido implicaba tres partidos. Las penas alcanzaban también a las entidades: en el caso de que algún equipo incluyera jugadores suspendidos o inhabilitados, se les descontaban dos puntos y se descalificaba al atleta por dos años. ${ }^{28}$

Los códigos, por su parte, implicaron una nueva fase de especialización en la represión y el castigo de las conductas indeseables y dispusieron de un status jurídico y documental independiente a los reglamentos. Aportaron una mayor puntualización y articulación entre los ilícitos, los infractores y sus penas, a fin de que estas últimas no quedaran sujetas al criterio subjetivo de los agentes que las juzgaban y se evitaran las disparidades al momento de su aplicación. Ya desde mediados de la década del diez, la prensa local exigía la implementación de marcos regulatorios deportivos que sistematizaran las conductas reprimibles, pero recién se sancionaron en la década siguiente.

El primer código del que se tiene registro es el de $1923 .^{29}$ Estaba organizado según la tipología de los hechos punibles, que afectaban más a las personas físicas (jugadores, dirigentes y referees) que a los clubes. Contemplaba no solo a aquellos que se producían en el desarrollo de la práctica deportiva misma, sino también a los de carácter burocrático. Entre los primeros estaban el juego brusco, los insultos o agresiones entre todos esos actores y el público, la discusión y el desacato a las órdenes del árbitro, el abandono del field por parte de jugadores y equipos y la presentación sin los uniformes reglamentarios. En relación con los segundos, se castigaba el profesionalismo (es decir, la percepción de compensaciones materiales por jugar), la firma por dos clubes de manera simultánea, la negativa a prestar declaración o redactar informes tras los partidos o a solicitud de las autoridades de la Liga, falsear testimonios, la adulteración de la fe de edad de los jugadores, la inclusión de otros inhabilitados y la omisión de presentar las planillas de resultados y las liquidaciones de los porcentajes correspondientes al ente oficial, entre otros. A cada uno de estos hechos le correspondía su propia pena según la gravedad de la situación: apercibimientos, amonestaciones, suspensiones o inhabilitaciones temporarias, descalificaciones, expulsiones, multas económicas y clausuras de canchas.

Con respecto a los reglamentos anteriores, además de añadir y precisar circunstancias, se modificaron algunas sanciones y sus alcances, ya que se contemplaron también los incidentes sucedidos al finalizar un partido y las reincidencias. A tono con el incremento de las transgresiones en las que tenían participación sujetos del público, estos comenzaron a ser igualmente objeto de regulaciones: cuando jugadores, dirigentes o referees de la LCF eran identificados propiciando altercados en calidad de espectadores, se les imponían castigos individuales; si los vándalos no podían ser reconocidos de entre ellos, la sanción recaía sobre el club al que adherían. De esta manera, cada uno de los actores era protegido y vigilado para favorecer la seguridad y prosperidad del espectáculo.

Los infractores también concibieron estrategias para impugnar el orden reglamentario y salvarse de una potencial sanción determinada por el código. Una de ellas fue la adulteración de los documentos arbitrales. En uno de esos casos, ante un incidente producido en un partido, dirigentes de un equipo redactaron el informe 
del referee con el objetivo de evitar que fuera castigado uno de sus jugadores, que había ingresado como parte del público al campo de juego a increpar al juez. El CD de la Liga pudo acreditar los hechos y la falsedad de los testimonios de los autores con base en pruebas caligráficas y el relato de varios testigos. Como este delito ya estaba tipificado en los códigos, las penas asignadas estuvieron acordes a lo determinado. ${ }^{30}$

Asimismo, los acusados por ilícitos no siempre aceptaron pasivamente las imputaciones o penas recibidas y recurrieron a canales extra institucionales para respaldar su posición. Uno de esos recursos consistía en el pronunciamiento público a través de la prensa. Así lo hizo el jugador Viera del club Nacional, con el fin de responder al informe del referee, quien sostenía que había sido insultado por los futbolistas de ese equipo. Al sentir su honor mancillado por la denuncia, apeló a una carta aclaratoria en la que desconocía la autoría del hecho y se la atribuía a los espectadores presentes. ${ }^{31}$ Era este uno de los mecanismos habituales a los que se acudía para librarse de un castigo y resguardarse de posibles arbitrariedades, desconocimientos o descuidos de las autoridades del orden e instigar a una investigación del caso.

El código de penas sufrió diferentes modificaciones de acuerdo a las nuevas prácticas que eran experimentadas en el deporte y la necesidad de arreglos normativos. Los niveles de codificación fueron cada vez más detallados. El Código aprobado en 1926 clarificaba los alcances de las sanciones y desagregaba las faltas sancionables para cada uno de los sectores sujetos a su jurisprudencia: las entidades afiliadas, sus dirigentes y jugadores y los referees, a los que se agregaron los miembros de los cuerpos directivos de la LCF. Por mencionar algunos delitos, el juego brusco era castigado con dos fechas de suspensión; el abandono de los campos de juego, una; firmar por dos clubes, un año; jugar estando suspendido, un año; referees actuando con parcialidad, dos años. Por otro lado, ante la sospecha de malversación de fondos y la búsqueda de mayor control del accionar de sus propios miembros, a los dirigentes que cumplían funciones para la Liga se les comenzó a exigir rendición de cuentas de los gastos efectuados. En general, las penas eran menores si respondían a acciones sucedidas durante el acto deportivo mismo mientras no se agrediera a las autoridades presentes; eran elevadas cuando transgredían principios éticos que regulaban la competencia o afectaban el patrimonio. Otro de los aspectos novedosos de esta legislación fue la disposición de castigos ante la inacción de las entidades para mantener el orden en los partidos o la falta de acondicionamiento de los campos de juego. ${ }^{32}$ Los clubes de mayores recursos estuvieron en mejores condiciones para invertir en estos aspectos y evitar, por ejemplo, el cambio de la localía, que sufrieron algunos clubes menos pudientes de primera división como Escuela Presidente Roca, Nacional o Instituto hasta que renovaron sus instalaciones.

El flamante código fue complementado con un nuevo tipo de documento para el registro de las penas aplicadas. El denominado Libro de Penas de la LCF del período 1927-1940, donde constaban las denuncias, los procedimientos ejecutados, las infracciones cometidas, sus autores y las sanciones que la entidad hacía efectivas, permitió tomar una real dimensión del cumplimiento de lo establecido en los códigos. A través de este se pudo comprobar que, siempre y cuando los hechos fueran informados y los acusados encontrados culpables, la pena impuesta coincidía con la estipulada para cada caso. ${ }^{33}$ Como se verá más adelante, las desavenencias burocráticas que aparecieron en torno a estos instrumentos legales no tuvieron tanto que ver con las normas jurídicas como con las relaciones de poder que intervenían en su aplicación.

Con relación al profesionalismo encubierto, en el cambio de década se incrementaron las denuncias. En realidad, se trataba de una práctica extendida entre los clubes más poderosos, quienes fichaban ilegalmente a los jugadores más talentosos. A partir de ese recurso, estos dispusieron de mayores posibilidades para mejorar su preparación física y técnica y así incrementar las diferencias con el resto. En 1930 aparecieron doce denuncias de entidades hacia jugadores de otros equipos. Dada la dificultad probatoria del hecho, el imputado solo fue suspendido en uno de esos casos. A veces, la denuncia era utilizada como una forma de desprestigiar a un rival y menguar su poderío, ya que los acusados no podían jugar mientras estuvieran siendo investigados. En los dos años que se sucedieron entre la implementación del profesionalismo en Buenos Aires (1931) y en Córdoba (1933), se descalificó a perpetuidad a 28 jugadores locales. ${ }^{34}$ En ese contexto, muchos de los mejores 
representantes del deporte cordobés fueron contratados por clubes porteños y rosarinos, acrecentando los desequilibrios existentes. Los castigos aplicados tenían más que nada un sentido disuasorio para los jugadores locales, ya que no tenían efectos prácticos en las ligas de destino. Una vez legalizado el profesionalismo, su condena desapareció de la reglamentación.

Desde entonces, nuevos aspectos comenzaron a ser legislados o esclarecidos en los códigos penales y registrados en los libros de actas. La definición de los hechos punibles continuó con su proceso de mayor personalización y precisión. Algunas penas conservaron su condena respecto a códigos anteriores, pero la gran mayoría se endureció, en un intento de combatir más enérgicamente la violencia y los ilícitos en el deporte. El objetivo que se proponían era "sanear" el espectáculo y atraer cada vez más público a los campos de juego, donde su integridad no corriera peligro y pudieran participar de una competencia justa y atractiva con resultados inciertos dentro de los marcos legales existentes. Ejemplo de ello fue la agresión al referee, cuyo castigo pasó a ser la expulsión de la cancha y la suspensión por un año; también la presentación de declaraciones testimoniales y documentales falsas, penalizadas con 6 meses y un año respectivamente. ${ }^{35}$

Otro de los cambios importantes de estos códigos fue la concesión de mayores garantías al acusado, como el acceso al derecho de la defensa y la inimputabilidad de quienes actuaban en defensa propia o no comprendían sus acciones por estar alterados en sus facultades ante la provocación sufrida. Además, se estipularon suspensiones provisionales a los imputados hasta que se resolviera el hecho denunciado, así como también se dictó la transferibilidad de las penas de un club a otro cuando el jugador cambiaba de equipo. Las condenas empezaron a comprender también a entrenadores y masajistas, ${ }^{36}$ dos nuevos actores del espectáculo deportivo surgidos en esos años a partir de la mayor especialización de la práctica, cuyas funciones eran la preparación física y técnica y el cuidado de la salud del plantel de jugadores para optimizar su rendimiento.

Una vez que todas las canchas oficiales comenzaron a contar con alambrado olímpico que los separaba del público, la habilitación de personas con acceso a los campos de juego fue otra de las medidas añadidas en el código de 1936. La disposición recogía una resolución emitida por la Liga en 1933 y autorizaba únicamente a los miembros del CD de la entidad federativa, presidente, secretario y tesorero del club local, linesman, entrenadores, masajistas, reporteros gráficos y un periodista por cada diario citadino y la policía. ${ }^{37}$ El propósito era evitar la aglomeración de gran cantidad de personas en los alrededores de los terrenos de juego, culpadas muchas veces de ser quienes iniciaban los desórdenes. El código de tres años después advirtió la ineficacia de la norma y la restringió aún más: de todos los cuadros dirigentes de las asociaciones deportivas, solo autorizó la presencia de los presidentes. ${ }^{38}$

Fuera de la LCF, cada liga o federación deportiva fue desarrollando sus reglamentos internos con sus propios dispositivos disciplinarios para la disputa de los torneos que organizaban. En gran parte, en ellos seguían el modelo amparado por el ente oficial del fútbol cordobés. Por ejemplo, Universitario hizo lo propio para la disputa del Campeonato Interprovincial entre estudiantes de las altas casas de estudios del país. ${ }^{39}$ Sin embargo, ninguna de estas entidades aficionadas alcanzó a lo largo de estos años niveles de formalidad tales como para necesitar contar con códigos de penas en la administración de justicia.

\section{LA AUTONOMIZACIÓN DE LOS ENTES DISCIPLINARIOS EN EL ESPECTÁCULO PROFESIONAL}

La sanción de los nuevos códigos fue acompañada, a partir de 1935, con la creación del Tribunal de Penas de la LCF. Se trataba de un organismo independiente a los intereses particulares de los clubes que se encargó de velar por la aplicación ecuánime de los reglamentos y que tuvo la capacidad para juzgar incluso a los mismos miembros de la Liga. Reemplazó la potestad que en el área disciplinaria tenía el CD. ${ }^{40}$ Junto con este último y la Asamblea, en dicho Tribunal pasó a residir la personería y autoridad de la Liga, lo que le confirió mayor legitimidad. 
El ente estaba compuesto por tres miembros titulares y dos suplentes designados anualmente por la Asamblea en votación secreta. Tres de los candidatos eran propuestos por el CD y dos por los delegados de los clubes de las categorías menores, con lo que se mantenían las disparidades ya existentes. No podían integrarlo los jugadores y los referees en actividad, los menores de 22 años, los delegados de las asambleas o del CD de la Liga ni los que habían sufrido penas disciplinarias. El órgano entendía en todo asunto que versara sobre la aplicación de las disposiciones punitivas en la sección Profesional del fútbol local de acuerdo a las penas establecidas en los códigos; en la sección Amateurs, solo podía apelar las resoluciones que dictaba el CD. Asimismo, mediaba en todas las cuestiones que se suscitaran entre los clubes afiliados. En todos los casos, resolvía con sujeción al Estatuto, al Reglamento General, al Código de Penas modificado oportunamente y de acuerdo con su creencia y conciencia. Sus fallos no podían ser discutidos por el CD, que debía acatar de inmediato sus resoluciones y velar por su cumplimiento. ${ }^{41}$ La adjudicación de esa cualidad legal le confería autoridad y respaldaba su posición autónoma en el ejercicio de las funciones jurídicas.

A juzgar por la memoria anual escrita por el entonces presidente de la Liga y uno de sus principales impulsores, el Dr. León Schwartz, la formación de este organismo con facultades disciplinarias respondía a las necesidades surgidas a partir de la instauración del profesionalismo. Ese nuevo marco, a su entender, requería ajustar el régimen punitivo ante "el peligro de que la moral y el decoro deportivo se perdiesen en la trama de intereses agudizados por el estímulo material que fomenta el football rentado" ${ }^{42}$

La percepción de las autoridades era que las prácticas mercantilistas estaban permeando todas las estructuras deportivas con un aire transgresor y amenazaban la reproducción de ciertos valores tradicionales vinculados al fair play y al respeto por el rival y por las reglas del juego, cuyo resguardo precisaba de una mayor codificación normativa y del control de entes independientes. Seguramente influyó en ese alegato lo sucedido el año anterior, cuando los clubes más poderosos y con mayor convocatoria de la Liga formaron mayoría en el $\mathrm{CD}$ y, sin que mediaran motivos deportivos, resolvieron el descenso de tres equipos e impidieron el ascenso de equipos de segunda. La medida fue justificada en términos financieros y significó la anulación arbitraria de los derechos deportivos de las instituciones consagrados por los reglamentos de la competencia. ${ }^{43}$

La prensa adhería a ese discurso de la existencia de un estado caótico que desmoralizaba al deporte y aseguraba que dentro y fuera de los campos de juego se repetían espectáculos bochornosos que alejaban a los aficionados del deporte ante el beneplácito de dirigentes y referees. Por esa razón, Schwartz impuso como condición para su reelección en el cargo de presidente la creación de un órgano disciplinario autónomo formado por deportistas con una reconocida trayectoria y que no pertenecieran a ninguno de los clubes locales. ${ }^{44}$

A partir de la información disponible no es posible asegurar que la profesionalización del fútbol haya generado un incremento exponencial en los incidentes y controversias alrededor de su práctica, más aún teniendo en cuenta que los cuadros amateurs no estuvieron exentos de ellos. Tampoco que haya conllevado per sé una merma del público, ya que las recaudaciones venían en baja desde inicios de los años treinta (en coincidencia con la crisis económica mundial) y no se recuperaron sino hacia finales de la década. Por el contrario, tal como se puede observar en el siguiente cuadro, las causas abiertas y acciones castigadas por los entes disciplinarios (registradas en el Libro de Penas) para todas las categorías del fútbol local habían aumentado considerable con la reforma de los reglamentos de la LCF en 1930, pero desde entonces estaban en franco descenso y continuaron decayendo tras la implementación de la práctica rentada. ${ }^{45}$ Sin embargo, en 1936 tuvieron un gran repunte en sintonía con la instauración del Tribunal y del nuevo código. 
TABLA 1

Registro de Libro de Penas de la LCF

\begin{tabular}{|l|l|}
\hline Año & $\begin{array}{l}\text { Causas } \\
\text { abiertas }\end{array}$ \\
\hline 1927 & 238 \\
\hline 1928 & 278 \\
\hline 1929 & 215 \\
\hline 1930 & 341 \\
\hline 1931 & 279 \\
\hline 1932 & 217 \\
\hline 1933 & 163 \\
\hline 1934 & 147 \\
\hline 1935 & 147 \\
\hline 1936 & 230 \\
\hline 1937 & 219 \\
\hline 1938 & 232 \\
\hline 1939 & 301 \\
\hline 1940 & 323 \\
\hline
\end{tabular}

Fuente: LCF, Libro de Penas, año 1927-1940

En realidad, de la lectura de los documentos se desprende que, más que un aumento en los incidentes, lo que efectivamente creció fue la cantidad de hechos investigados y sanciones aplicadas. Esa mayor actividad disciplinaria coincidía con el reclamo de la prensa y del presidente de la Liga de que hasta entonces era "letra muerta" todo aquello que indicara castigo para jugadores o dirigentes mientras se tratara de clubes profesionales. Su afirmación se apoyaba en que, a pesar de ser minoría los equipos que contaban con jugadores remunerados, ${ }^{46}$ tenían la mayoría de la representación en el CD. ${ }^{47} \mathrm{~A}$ partir de esa asimetría eran acusados de hacer valer sus influencias y poder de negociación para sortear y evadir las medidas disciplinarias. Más allá de que estas maniobras no dejaban evidencias y de que tampoco se haya hallado información suficiente para poder reconstruirlas (a través de los documentos que se producían en relación con los incidentes y el castigo a los culpables), era innegable la merma en las investigaciones y puniciones de los ilícitos. Probablemente, pudo haber ayudado el hecho de que las sanciones no siempre se asentaran en los informes arbitrales o de que en ocasiones estos fueran archivados sin abrirse causas.

Sin embargo, lo que los mencionados desajustes en el sistema punitivo dejaron en entredicho fue la supuesta tendencia progresiva en la normativización disciplinaria que se venía dando desde los años veinte. Más bien, su mayor eficacia y racionalización encontró límites en los intereses particulares que cada club impuso en sus interrelaciones competitivas, lo cual acrecentaba los desequilibrios entre los equipos y explica también la demanda de nuevas estructuras jurídicas.

Las estadísticas, entonces, no ofrecen mayores precisiones sobre variaciones cuantitativas en los incidentes propiamente dichos. Sin embargo, es posible advertir un cambio en la percepción sobre estos hechos a partir del auge de un tipo concreto de ilícito que adquirió relevancia a partir de la profesionalización: los sobornos. Se trataba del ofrecimiento directo o por vía de un intermediario de dinero, objetos, trabajo u otros incentivos a un jugador, dirigente o referee. El objetivo era conseguir de ellos un beneficio, un favor o el incumplimiento de sus obligaciones para favorecer a la parte oferente. En tiempos de actividad deportiva rentada, el afán de ganar partidos y lograr el título de campeonato significaba la posibilidad de percibir mayores ingresos para jugadores y clubes, además del reconocimiento público que tal logro significaba. Estos fenómenos de corrupción causaban escepticismo en el ambiente y ponían en tela de juicio la honestidad y ética deportiva de los jugadores, sobretodo en momentos de definición de los torneos. Nuevamente quedaba afectado, entonces, uno de los principios éticos fundamentales en los que se basaba el fútbol en su dimensión lúdica y competitiva: la igualdad de condiciones de la que partían los rivales, que era un componente esencial del imaginario 
democrático de los deportes. El repudio y persecución de esos ilícitos se convirtió en un objetivo de las autoridades de la LCF, como una forma también de restituir la justicia inicial entre los rivales (Cfr. Reyna, 2019).

Con relación a su funcionamiento, el Tribunal de Penas tuvo un papel reformatorio acorde a la fama que lo precedía: aplicando estrictamente el sistema de normas jurídicas de los códigos de penas, resolvió anualmente un promedio de 60 a 80 expedientes abiertos que llegaban a sus fueros, los que se saldaban con expulsiones, suspensiones, apercibimientos, llamados de atención o sobreseimientos a jugadores, referees, linesman, masajistas, entrenadores, capitanes, dirigentes y clubes. ${ }^{48}$ Toda su actuación era asentada en registros burocráticos creados a fin de formalizar su labor jurídica: el libro de Actas del Tribunal de Penas, donde labraban las actas de sus reuniones, y el Tribunal de Penas, donde transcribían por orden cronológico las resoluciones adoptadas caso por caso. El organismo intervino también en tareas de prevención de los delitos al distribuir entre jugadores, dirigentes y referees los ejemplares del reformado Código de Penas para lograr una mayor difusión y aprendizaje de los reglamentos vigentes. ${ }^{49}$

En acuerdo con lo sancionado en el código de 1938, que extendió sus alcances regulatorios a los socios de los clubes, el Tribunal fue habilitado a suspender o expulsar en tal carácter a los que entre estos fueran identificados participando de algún desorden, lo cual debía ser inmediatamente cumplido por la institución a la que pertenecían. ${ }^{50}$ Además, se impusieron penas drásticas para los sobornos a jugadores: al año siguiente, con mayor experiencia en el abordaje de esos casos, el Tribunal pudo comprobar la culpabilidad de un dirigente en un cohecho y lo inhabilitó perpetuamente para ocupar cargos directivos; además, el club Peñarol suspendió a tres de sus jugadores por 99 años. ${ }^{51}$

La autonomía de este órgano frente al Poder Ejecutivo de la Liga y a otras asociaciones del ámbito deportivo generó inconvenientes en torno a las atribuciones jurisdiccionales de cada una. Un claro ejemplo fue el mencionado conflicto que tuvo con la asociación de referees, que derivó en una huelga de estos últimos. Además, cuando el cuerpo era desoído y se sentía agraviado en sus fueros, generaba la renuncia de sus miembros. Eso sucedió en noviembre de 1941 ante una investigación por sobornos, en la que el Tribunal no sancionó a los inculpados por no hallarse el caso específicamente contemplado en el Código de Penas, pero la Asamblea Extraordinaria de la Liga igualmente resolvió condenarlos, lo que propició la reacción del organismo disciplinario. ${ }^{52}$

Los jugadores no resultaron ajenos a todas estas transformaciones y también construyeron sus propias representaciones en torno al orden moral y la justicia en el deporte a partir de la creación del Tribunal. La prensa los consultaba sobre esta nueva institución disciplinaria y publicaba sus opiniones siempre favorables. Emilio Castro consideraba que era una medida necesaria para moralizar el ambiente y poner orden en el deporte; ${ }^{53}$ Dionisio López lo veía como un instrumento para velar por la integridad física de los jugadores y para el respeto a los referees; ${ }^{54}$ Pedro Basílico exponía que en el medio local existía una falta evidente de entrenamiento debido a las malas direcciones técnicas y los arbitrajes eran poco capaces y abusaban de su poder, lo cual debería ser castigado también por el organismo. ${ }^{55}$ Más allá de ser lo que se esperaba que respondieran en esas circunstancias, los entrevistados no descalificaban las normas y valores que regían al juego ni su contenido "civilizatorio", sino que exigían mayores garantías para su cumplimiento con miras a favorecer marcos más adecuados para el desarrollo de su práctica. $\mathrm{Al}$ reconocer el cuadro de sospechas y violencia en el que estaba inmerso el campo deportivo, mostraban la conveniencia del novedoso dispositivo legal, ya que por su carácter independiente era una herramienta que podía servir para "recomponer" el ambiente, defender sus propios intereses de las arbitrariedades de las autoridades y propiciar mayor igualdad en la administración de justicia. Avalaban también el hecho de que actuara y aleccionara sobre las conductas de todos los actores del campo deportivo que incurrían en hechos de injusticia o coacción.

En definitiva, la instauración de este ente, así como de los diferentes mecanismos institucionales que respaldaron su accionar, se convirtió en uno de los resortes más importantes que tuvo la Liga para el 
cumplimiento de una de sus principales atribuciones: el resguardo del orden y la corrección en la práctica deportiva.

\section{Conclusión}

La administración de justicia fue un aspecto central en el proceso de institucionalización de la práctica del fútbol. En tanto instancia que regía las relaciones entre las personas y las asociaciones deportivas, de ella dependió la definición de las normas de comportamiento deseadas y la elaboración de procedimientos y estructuras burocráticas para la identificación, el procesamiento y el castigo a sus infractores. Esa tarea estuvo a cargo de las federaciones deportivas que agrupaban a los clubes locales y auspiciaban sus competencias. La LCF, como una de ellas, estableció sus propios instrumentos disciplinarios para el desarrollo de la actividad y acordó las funciones y atribuciones de sus órganos de ejecución tanto dentro (los referees) como fuera (CD, Jury de Honor, Tribunal de Penas) de los campos de juego. Uno de sus principales objetivos fue proveer un marco de interacción armónica entre los participantes, de modo que, en términos legales, todos partieran desde una posición inicial que igualara sus oportunidades en el juego.

Los agentes y las instituciones jurídicas adaptaron permanentemente sus estructuras y reglamentaciones a los diferentes cambios que fue atravesando la actividad deportiva, en pleno proceso de espectacularización y mercantilización. Su labor estuvo signada por una lógica liberal, a partir de la que el derecho jurídico y la igualdad aparecían como los fundamentos centrales que resguardaban las libertades de los participantes y delimitaban los valores que se esperaban de ellos para el progreso de la práctica. Los deportistas atribuyeron el monopolio de la autoridad en materia penal a la LCF y mayormente le concedieron legitimidad a sus formas de instrumentar el poder punitivo. Sin embargo, aunque las normas unificadas para el conjunto de los actores se sostuvieran en ese principio de igualdad ante la ley, en ninguno de los casos atendía las condiciones particulares y las asimetrías ya existentes entre los individuos y las asociaciones implicados; además, hasta la creación del Tribunal de Penas, la aplicación de las sanciones estuvo sujeta a estructuras de poder que respondían a intereses particulares de los clubes. De esta manera, la desigualdad de resultados perduraba y era generalmente aceptada mientras mediaran procedimientos equitativos. Cuando se percibían arbitrariedades que afectaban el honor personal y generaban desequilibrios entre los competidores, las normas fueron objeto de interpretaciones ambiguas, negociaciones o impugnaciones, a las que también apelaban quienes buscaban obtener ventajas de sus rivales.

A lo largo de estos años, entonces, las conductas en el ámbito deportivo fueron sometidas a un proceso de mayor racionalización y codificación, al tiempo que sus órganos disciplinarios estuvieron inmersos en conflictos y disputas por su descentralización y democratización. Gracias a ello pudieron ir paulatinamente alcanzando mayores niveles de autonomía de los poderes ejecutivos de la liga e independencia de los clubes.

Un nuevo orden jurídico especializado fue emergiendo para regular el sistema de sanciones y castigos deportivos. La formalización institucional y la modernización de las estructuras organizativas y disciplinarias dotaron a la práctica de mayores garantías y seguridades y generaron las condiciones para su conversión en un producto cultural de masas. De esta manera, la transformación del sistema competitivo con miras a establecer marcos reguladores más claros y objetivos fue uno de los principales aspectos que favoreció el desarrollo del futbol como espectáculo y la expansión del mercado deportivo.

\section{ReFERENCIAS}

Frydenberg, J. (2011). Historia Social del fútbol. Del amateurismo a la profesionalización. Buenos Aires: Sudamericana. Ortiz Bergia, M. J. (2012). La Construcción del Estado Social en el Interior Argentino. Cambios y Continuidades en las Politicas Sociales en Córdoba, 1930-1955 (Tesis Doctoral inédita). Universidad Nacional de Córdoba, Córdoba. 
Remedi, F. (2004). El consumo alimentario en la Provincia de Córdoba 1870-1930 (Tesis Doctoral inédita). Universidad Católica de Córdoba, Córdoba.

Reyna, F. (2011). Cuando éramos footballers. Una historia sociocultural del surgimiento y difusión del fútbol en Córdoba (1900-1920). Córdoba: CEH.

Reyna, F. (2018). La desigualdad en las estructuras competitivas del fútbol profesional de Córdoba (Argentina) en la década del treinta. Folia Histórica del Nordeste, (33), 161-182.

Reyna, F. (2019). Jugar al fútbol en la Córdoba (Argentina) de entreguerras: la conformación de subjetividades e identidades en el deporte. Secuencia, (103), 1-34.

Roldán, D. (2012). La invención de las masas: ciudad, cuerpos y culturas. Rosario, 1910-1945. La Plata: Universidad Nacional de La Plata.

\section{Notas}

1 Los Principios (LP), 13 de junio de 1915, p. 6. Años después los carnets incluían retratos fotográficos. Los datos consignados eran el nombre y apellido, club al que pertenecían, número de matrícula, fecha de nacimiento y de otorgamiento del documento y las firmas del jugador y del secretario de la LCF. LCF, Carnets, años 1938-1939.

2 La Voz del Interior (LVI), 19 de febrero de 1916, p. 5.

3 LP, 01 de febrero de 1917, p. 6. Según los documentos existentes de la LCF, los libros de firmas inician en el año 1921.

4 Los registros más antiguos que se conservan en la LCF datan del año 1924.

5 Los primeros registros existentes en la LCF son de 1927.

6 LCF, Estatuto y Reglamento General, Los Principios, Córdoba, 1916, pp. 31-33.

7 LP, 07 de marzo de 1915, p. 12; LVI, 12 de junio de 1923, p. 11 . A modo de referencia, el kilo de pan en 1924, año del que existen referencias, costaba $\$ 0,33$ (Remedi, 2004, p. 333).

8 LCF, Boletín Oficial, núm. 39, año 1924.

9 Ante esta situación, los partidos podían jugarse solo si los capitanes acordaban en la elección como referee de alguno de los aficionados presentes (Reyna, 2011, p. 89).

10 LCF, Copiadores, núm. 5, año 1926, f. 350.

11 LVI, 09 de abril de 1930, p. 15.

12 LCF, Estatutos, año 1930, pp. 31-43.

13 LCF, Libro de Penas a Jugadores, Dirigentes y Referees, 1927-1940.

14 LP, 11 de mayo de 1933, p. 16.

15 LCF, Boletín Oficial, núm. 430, año 1933.

16 LVI, 04 de octubre de 1933, p. 13.

17 Una de esas veces, en la que el presidente y el secretario de la asociación fueron suspendidos por un año por cuestionar una resolución del Tribunal de Penas, el asunto desencadenó otra huelga de árbitros. La LCF contaba ahora con estrategias para revertir la situación: escindió a la ACAF de su seno, ultimó a sus miembros a que ratificaran su inscripción como árbitros oficiales y abrió una nueva convocatoria para aspirantes. Todas estas medidas quedaron anuladas al rever la asociación su postura. LVI, 04 de octubre de 1939, p. 12; 05 de octubre de 1939, p. 12; 06 de octubre de 1939, p. 12; 07 de octubre de 1939, p. 11.

18 LP, 19 de septiembre de 1933, p. 11.

19 LVI, 10 de marzo de 1926, p. 15.

20 LVI, 18 de febrero de 1934, p. 14.

21 LP, 04 de mayo de 1934, p. 10.

22 LCF, Libro de Actas Subcomisión de Referees, años 1936-1945.

23 LCF, Tribunal Calificador de Referees. Cómputos, año 1939. Para establecer una comparación, al iniciar 1940 un salario de empleados de comercio (con capacidad de acceso a créditos) podía oscilar entre los 180 y los 300 pesos (Ortiz Bergia, 2012, p. 67).

24 LVI, 10 de enero de 1926, p. 14.

25 LVI, 18 de marzo de 1927, p. 14.

26 LVI, 23 de octubre de 1939, p. 12.

27 En un artículo previo se analizó más detalladamente las implicancias institucionales de esa desigual distribución de poder entre los miembros de la Liga (Reyna, 2018).

28 LCF, Estatuto y Reglamento General, Los Principios, Córdoba, 1916, pp. $24-27$.

29 LVI, 17 de mayo de 1923, p. 15. 
30 LVI, 06 de mayo de 1926, p. 14 y 08 de mayo de 1926, p. 14.

31 LVI, 23 de septiembre de 1923, p. 13.

32 LCF, Código de Penas, s/d, Córdoba, 1926.

33 LCF, Libro de Penas a Jugadores, Dirigentes y Referees, año 1930, f. 42.

34 LCF, Libro de Penas a Jugadores, Dirigentes y Referees, años 1930-1933, f. 42.

35 LCF, Código de Penas, s/d, Córdoba, 1936.

36 LCF, Código de Penas, cit.

37 LVI, 25 de agosto de 1933, p. 14.

38 LCF, Código de Penas, s/d, Córdoba, 1936.

39 LVI, 31 de mayo de 1928, p. 12.

40 El Código de 1926 menciona la existencia de otro ente jurídico de la LCF, el Jury de Honor, pero no contamos con mayor información de su funcionamiento.

41 LCF, Estatutos, s/d, Córdoba, 1935, pp.40-45.

42 LCF, Actas de Asamblea, Tomo 2, 14 de febrero de 1936, fs. 141-140.

43 Para mayor información consultar: Reyna (2018).

44 LVI, 09 de mayo de 1935, p. 14.

45 En otra investigación se dio cuenta de las sanciones aplicadas, pero restringidas a jugadores y dirigentes (Reyna, 2019).

46 Solo podían los equipos que participaban de la división superior de la LCF, cuyo número fue variando en los diferentes años entre 6 y 10 de un total de 21 o 24 inscriptos en las diferentes categorías.

47 LCF, Estatutos, s/d, Córdoba, 1935, p. 22.

48 LCF, Tribunal de Penas, años 1936-1942.

49 LVI, 30 de abril de 1936, p. 15.

50 LCF, Código de Penas, año 1938.

51 LCF, Tribunal de Penas. Penas aplicadas, año 1939, f. 19.

52 LCF, Actas de Asamblea, Tomo 3, 24 de noviembre de 1941, fs. 83-88; LVI, 27 de noviembre de 1941, p. 14.

53 LP, 19 de mayo de 1935, p. 16.

54 LP, 23 de junio de 1935, p. 14.

55 LP, 15 de mayo de 1935, p. 9. 